\title{
MỐI QUAN Hệ Độ PHÂN GIẢI CỦA ẢNH VÀ Độ CHÍNH XÁC THÀNH LẬP, HIỆN CHİNH BẢN ĐỒ ĐỊA HİNH TỶ LẸ 1:2.000 VÀ 1:5.000
}

\author{
TS. ĐÀO NGỌC LONG(1), ThS. PHAM NGỌC SO'N(2) \\ (1)Viện Khoa học Đo đạc và Bản đồ \\ ${ }^{(2)}$ Cục Bản đồ Quân đội
}

\section{Tóm tắt:}

Rất nhiều nghiên cứu đã bàn về độ phân giải của ảnh (ảnh vệ tinh, ảnh hàng không) liên quan đến tỷ lệ bản đồ cần thành lập nói chung. Ở Việt Nam, quy định kỹ thuật trong công tác bay chụp ảnh hàng không kỹ thuật số dạng chụp khung trong công tác thành lập, hiện chỉnh bản đồ địa hình chưa được ban hành. Bài báo giới thiệu một số vấn đề liên quan đến mối quan hệ độ phân giải của ảnh và độ chính xác thành lập, hiện chỉnh bản đồ địa hình tỷ lệ 1:2.000, 1:5.000.

\section{Tổng quan về độ phân giải trong thành lập và hiện chỉnh bản đồ địa hình}

Trong công nghệ đo vẽ ảnh (ảnh tương tự, bán giải tích, giải tích hay bán số) sử dụng phim nhựa truyền thống chúng ta thường sử dụng các khái niệm tỷ lệ ảnh, mức độ chi tiết của đối tượng chụp biểu thị bằng số cặp đường trên một milimet $(\mathrm{Ip} / \mathrm{mm})$ (line pairs per unit distance) và phụ thuộc vào các loại phim (kích thước của hạt halogen bạc) hay phụ thuộc vào độ nhạy của phim (phim có độ nhạy càng lớn kích thước hạt halogen bạc càng lớn và số cặp đường $\mathrm{lp} / \mathrm{mm}$ càng ít). Độ phân giải của phim ảnh sau khi tráng rửa là độ phân giải của hệ thống máy ảnh - phim chụp và phụ thuộc vào các yếu tố chính sau đây: 1/Độ phân giải của kính vật máy ảnh; 2/Độ phân giải của phim chụp (phim âm hoặc phim sao dương); 3/Độ nhoè của hình ảnh trong khi lộ quang (gây ra bởi tốc độ của máy bay, chuyển động xoay của giá máy ảnh); 4/Quá trình xử lý hoá ảnh (tráng rửa phim ảnh chụp được); 5/Điều kiện thời tiết và môi trường khí quyển tại thời điểm bay chụp; 6/Độ tương phản của địa hình khu chụp.
Với các tiến bộ của các công nghệ sản xuất máy ảnh và phim chụp ảnh hàng không, ba yếu tố đầu có thể được khắc phục đáng kể. Hai yếu tố sau cùng mặc dù đóng vai trò không kém phần quan trọng so với ba yếu tố đầu nhưng lại hầu như không thể kiểm soát được bởi con người. Độ phân giải của kính vật máy ảnh và độ phân giải của phim chụp là các yếu tố hoàn toàn mang tính công nghệ. Độ nhòe của hình ảnh trong khi lộ quang một mặt phụ thuộc vào các tính năng của công nghệ như: tốc độ và độ ổn định của máy bay dùng để bay chụp, bộ cân bằng tự động của giá máy ảnh; mặt khác lại phụ thuộc vào tay nghề và kinh nghiệm của phi công, hoa tiêu và người điều khiển máy chụp ảnh trên không. Hai yếu tố sau cùng có tính chất đặc trưng, phân biệt giữa vùng này với vùng khác trong một nước, giữa các nước với nhau. Các máy ảnh hiện đại như: Leica - Wild RC30, Zeiss RMK Top 15 hay LMK-2000có độ phân giải của kính vật vào khoảng $95 \mathrm{lp} / \mathrm{mm}$ (cặp đường trên milimét). Tuỳ theo độ tương phản của hình ảnh mà độ phân giải của phim chụp hiện nay dao động trong 
khoảng từ $55 \mathrm{Ip} / \mathrm{mm}$ đến $130 \mathrm{lp} / \mathrm{mm}$. Độ nhòe do sự dịch chuyển về phía trước của hình ảnh có giá trị trung bình khi chuyển sang $\mathrm{lp} / \mathrm{mm}$ là $83 \mathrm{lp} / \mathrm{mm}$. Độ nhòe của hình ảnh do chuyển động xoay của giá máy ảnh có giá trị trung bình là $48 \mathrm{lp} / \mathrm{mm}$. Độ phân giải của phim sao là $100 \mathrm{lp} / \mathrm{mm}$ (Light, 1996).

Với các quy định đã ban hành từ trước chỉ quy định khoảng tỷ lệ cho bay chụp với loại bản đồ nói chung chứ không quy định rõ áp dụng cho khoảng cao đều (hay độ chính xác xác định độ cao). Đối với máy ảnh hàng không kỹ thuật số dạng chụp khung, khái niệm mức độ chi tiết của đối tượng chụp biểu thị bằng số cặp đường trên một milimet $(\mathrm{Ip} / \mathrm{mm})$ được thay thế bằng "Độ phân giải mặt đất (Ground Resolution)" hay là khoảng cách lấy mẫu mặt đất (Ground Sampling Distance) hoặc kích thước pixel (Pixel Size) là kích thước của 1 pixel trên mảng $C C D$ của máy chụp ảnh chiếu trên mặt đất. Tuy có nhiều khái niệm khác nhau nhưng bản chất độ phân giải mặt đất cũng được tính từ kích thước Pixel của CCD, độ cao bay chụp, tiêu cự bay chụp hay tỷ lệ của ảnh.

$$
\mathrm{GSD}=\frac{\mathrm{Ha}}{f c}{ }^{*} \text { kích thước pixel }
$$

Với: $\mathrm{H}_{\mathrm{a}}$ : độ cao bay chụp, $\mathrm{f}_{\mathrm{c}}$ : tiêu cự máy chụp ảnh.

Các yếu tố ảnh hưởng đến độ phân giải mặt đất là: tiêu cự, độ cao bay chụp, các ảnh hưởng của khí quyển. Một tấm ảnh độ phân giải thấp có thể cho phép đo vẽ các đối tượng lớn, trong khi một tấm ảnh độ giải cao cho phép đo vẽ được các chi tiết nhỏ trên mặt đất. Theo Jacobsen [4] độ phân giải mặt đất để có thể xác định rõ địa vật trên bản đồ là từ 0,05 tới $0,1 \mathrm{~mm}$ tính theo tỷ lệ bản đồ, một số tài liệu khác lại cho rằng từ 0,07 tới $0,1 \mathrm{~mm}$ theo tỷ lệ bản đồ. Tuy nhiên, tùy thuộc vào yêu cầu thành lập hay hiện chỉnh bản đồ tỷ lệ nào, độ chính xác xác định độ cao bao nhiêu cần phải có ước tính độ phân giải chụp ảnh cho phù hợp

\section{Mối quan hệ giữa độ phân giải và độ chính xác xác định độ cao}

Như đã đề cập ở trên, độ phân giải của ảnh hàng không kỹ thuật số theo nghiên cứu của K.Jacobsen độ phân giải mặt đất (GSD) được xác định trong khoảng từ $0.05 \mathrm{~mm}$ đến $0.1 \mathrm{~mm}$ ở tỷ lệ bản đồ cần thành lập. Ví dụ với tỷ lệ bản đồ là 1:2.000 thì độ phân giải mặt đất (GSD) cần đạt được là từ $0.1 \mathrm{~m}$ đến $0.2 \mathrm{~m}$.

Với công thức (1) trên, nếu biết tiêu cự, kích thước Pixel của CCD máy chụp ảnh chúng ta dễ dàng tính được độ cao bay chụp. Tất nhiên, với độ phân giải có khoảng dao động (thí dụ: tỷ lệ 1:2.000 từ 0.1 đến $0.2 \mathrm{~m}$ ) chúng ta cũng sẽ có khoảng từ độ cao bay chụp này đến độ cao bay chụp khác tương ứng.

Các hãng sản xuất máy chụp ảnh hàng không cũng có những khuyến cáo về mối quan hệ độ phân giải mặt đất và độ chính xác thành lập bản đồ.

Theo PurVIEW (C) I.S.M International Systemap Corp thì mối quan hệ tỷ lệ bản đồ, khoảng cao đều, độ chính xác $(x, y, z)$ và độ phân giải mặt đất như sau: (Xem bảng 1)

Hãng Leica Geosystems cũng có khuyến cáo cho máy chụp ảnh dạng quét ADS80 Brochure. (Xem bảng 2)

Cơ quan phát triển không gian Quốc gia Nhật Bản (NASDA) cũng có khuyến cáo về mối quan hệ giữa tỷ lệ bản đồ, độ chính xác, độ phân giải tùy theo từng mục đích sử dụng. (Xem bảng 3)

Với các khuyến cáo như vậy, việc xác định độ phân giải như thế nào cho phù hợp cũng gặp phải những khó khăn nhất định như với cùng tỷ lệ bản đồ cần thành lập Việt Nam có thể có hai loại khoảng cao đều tùy thuộc vào độ dốc của địa hình (theo phân loại của quy phạm hiện hành). Chính vì vậy, 
Bảng 1: Mối quan hệ tỷ lệ bản đồ, khoảng cao đều, độ chính xác $(x, y, z)$ và độ phân giải

\begin{tabular}{|c|c|c|c|c|c|}
\hline \multirow{2}{*}{$\begin{array}{c}\text { Tỷ lệ bản } \\
\text { đồ }\end{array}$} & \multirow{2}{*}{\begin{tabular}{|c|} 
Khoảng cao đều \\
$(\mathrm{m})$
\end{tabular}} & \multicolumn{3}{|c|}{ Độ chính xác (m) } & \multirow{2}{*}{$\begin{array}{l}\text { GSD } \\
(\mathrm{cm})\end{array}$} \\
\hline & & $\mathbf{X}$ & $\bar{Y}$ & $\mathbf{Z}$ & \\
\hline $1: 500$ & 0.5 & 0.25 & 0.25 & 0.25 & 5 \\
\hline 1: 1.000 & 1 & 0.5 & 0.5 & 0.5 & 10 \\
\hline $1: 2.000$ & 2 & 1 & 1 & 1 & 20 \\
\hline $1: 5.000$ & 5 & 2.5 & 2.5 & 2.5 & 50 \\
\hline 1: 10.000 & 10 & 5 & 5 & 5 & 100 \\
\hline 1: 20.000 & 20 & 10 & 10 & 10 & 200 \\
\hline $1: 50.000$ & 50 & 25 & 25 & 25 & 500 \\
\hline
\end{tabular}

Bảng 2: Quan hệ độ phân giải mặt đất và độ chính xác thành lập bản đồ địa hình

\begin{tabular}{|c|c|c|c|}
\hline \multirow{2}{*}{} & \multicolumn{3}{|c|}{ Độ chính xác bản đồ địa hình } \\
\cline { 2 - 4 } & \multirow{2}{*}{$\begin{array}{c}\text { Tỷ lệ } \\
\text { bản đồ }\end{array}$} & \multicolumn{2}{|c|}{ Tiêu chuẩn bản đồ } \\
\cline { 3 - 4 } & $\begin{array}{c}\text { Sai số trung phương theo } \\
\text { hướng } \mathbf{X} \text { hoặc } Y \text { (RMS) }\end{array}$ & $\begin{array}{c}\text { Khoảng cao } \\
\text { đều cơ bản }\end{array}$ \\
\hline $5-10 \mathrm{~cm}$ & $1: 500$ & $0.125 \mathrm{~m}$ & $0.25 \mathrm{~m}$ \\
\hline $10-15 \mathrm{~cm}$ & $1: 1.000$ & $0.25 \mathrm{~m}$ & $0.5 \mathrm{~m}$ \\
\hline $20-30 \mathrm{~cm}$ & $1: 2.000$ & $0.50 \mathrm{~m}$ & $1 \mathrm{~m}$ \\
\hline $35-50 \mathrm{~cm}$ & $1: 5.000$ & $1.25 \mathrm{~m}$ & $2.5 \mathrm{~m}$ \\
\hline $40-60 \mathrm{~cm}$ & $1: 10.000$ & $2.5 \mathrm{~m}$ & $5 \mathrm{~m}$ \\
\hline $50-80 \mathrm{~cm}$ & $1: 20.000$ & $6.25 \mathrm{~m}$ & $12.5 \mathrm{~m}$ \\
\hline $50-100 \mathrm{~cm}$ & $1: 50.000$ & $12.5 \mathrm{~m}$ & $20 \mathrm{~m}$ \\
\hline $50-100 \mathrm{~cm}$ & $1: 100.000$ & $25 \mathrm{~m}$ & $50 \mathrm{~m}$ \\
\hline
\end{tabular}

Bảng 3: Quan hệ tỷ lệ, độ chính xác và độ phân giải (Nguồn: Produced by National space Development agency of Japan (NASDA))

\begin{tabular}{|c|c|c|c|c|c|c|}
\hline \multirow{2}{*}{ Tỷ lệ BĐ } & \multicolumn{3}{|c|}{ Độ chính xác } & \multicolumn{2}{c|}{ Độ phân giải } & \multirow{2}{*}{$\begin{array}{c}\text { Mục đích } \\
\text { sứ dụng }\end{array}$} \\
\cline { 2 - 6 } & $\begin{array}{c}\text { Khoảng } \\
\text { cao đều }\end{array}$ & $\begin{array}{c}\text { Độ chính } \\
\text { xác độ cao }\end{array}$ & $\begin{array}{c}\text { Độ chính } \\
\text { xác mặt }\end{array}$ & $\begin{array}{c}\text { Khoảng } \\
\text { cách }\end{array}$ & $\begin{array}{c}\text { Kích } \\
\text { thước }\end{array}$ & \multirow{2}{*}{} \\
\cline { 2 - 6 } & $\mathbf{( m )}$ & $\mathbf{( m )}$ & phẳng $(\mathbf{m})$ & GRID $(\mathbf{m})$ & Pixel $(\mathbf{m})$ & \\
\hline 1: 500 & 0.5 & 0.17 & 0.25 & 0.5 & 0.05 & Địa chính \\
\hline 1: 1.000 & 1 & 0.3 & 5 & 1 & 0.1 & Địa chính, khác \\
\hline 1: 2.000 & 2 & 0.7 & 1.25 & 2.5 & 0.25 & Quy hoạch thành phố \\
\hline 1: 5.000 & 5 & 1.7 & 2.5 & 5 & 0.5 & Quy hoạch thành phố \\
\hline 1: 10.000 & 10 & 3 & 5 & 10 & 1 & Bản đồ thành phố \\
\hline 1: 20.000 & 12,20 & 3,7 & 12.5 & 25 & 2.5 & Bản đồ địa hình cơ sở \\
\hline 1: 50.000 & 20,40 & 7,13 & 25 & 50 & 5 & Bản đồ địa hình cơ sở \\
\hline 1: 100.000 & 50 & 17 & 50 & 100 & 12 & Quy hoạch vùng \\
\hline 1: 250.000 & 100 & 33 & 125 & 250 & 25 & Bản đồ tài nguyên \\
\hline 1: 500.000 & 100,200 & 33,66 & 250 & 500 & 50 & Bản đồ tài nguyên \\
\hline 1: 1.000 .000 & 200 & 66 & 500 & 1000 & 100 & Bản đồ giao thông, hàng hải \\
\hline
\end{tabular}


việc ước tính độ phân giải hay độ cao bay chụp, tiêu cự máy chụp cho từng loại bản đồ tương ứng với khoảng cao đều (hoặc độ chính xác xác định độ cao) là hết sức cần thiết. Mặt khác, khi chỉ sử dụng cho hiện chỉnh hoặc đo vẽ bản đồ địa vật không đo vẽ yếu tố địa hình thì việc xác định độ phân giải phù hợp mang hiệu quả kinh tế cao hơn, quy định kỹ thuật cũng thể hiện sự rõ ràng hơn.

\subsection{Cơ sở khoa học của xác định độ cao bay chup}

Theo công nghệ truyền thống trước đây, công tác bay chụp ảnh hàng không việc xác định độ cao bay chụp phân hai loại rõ ràng: bay chụp cho đo vẽ lập thể và bay chụp cho phương pháp đo vẽ phối hợp. Đây là phương pháp nắn, thành lập bình đồ ảnh và đo địa hình trực tiếp ngoài thực địa. Phương pháp này khi xác định độ cao bay chụp người ta quan tâm lớn nhất chính là sai số xê dịch vị trí điểm ảnh do chênh cao địa hình gây ra. Hiện nay, với công nghệ đo vẽ ảnh số phương pháp này gần như đã bị loại bỏ trong các phương pháp thành lập bản đồ địa hình theo công nghệ ảnh số. Với sự phát triển của khoa học công nghệ, ảnh viễn thám với độ phân giải cao có thể thay thế cho ảnh chụp từ máy ảnh hàng không kỹ thuật số với mục đích sử dụng là đo vẽ các yếu tố địa vật. Chính vì vậy, việc xác định độ cao bay chụp - tỷ lệ ảnh - độ phân giải mặt đất cho các ứng dụng đo vẽ bản đồ địa hình tương ứng với tỷ lệ, khoảng cao đều cần thành lập và độ cao bay chụp - tỷ lệ ảnh độ phân giải mặt đất cho các ứng dụng công nghệ ảnh nhưng không liên quan nhiều đến độ chính xác xác định độ cao (chủ yếu mặt phẳng) là chính. Việc chọn độ cao bay chụp, tiêu cự máy chụp ảnh và tỷ lệ chụp ảnh và bản chất chính là xác định độ phân giải mặt đất của ảnh chụp. Có hai vấn đề cần quan tâm đó là: tính kinh tế và độ chính xác. Để giảm bớt chi phí cho công tác bay chụp, công tác đo đạc khống chế ảnh ngoại nghiệp, công tác đo vẽ nội nghiệp, đối với bất cứ tỷ lệ bản đồ nào cần thành lập việc chọn độ cao bay chụp lớn nhất, tiêu cự máy chụp ảnh ngắn nhất (ống kính góc rộng) luôn có lợi về kinh tế. Tuy nhiên, việc tăng độ cao bay, tiêu cự ngắn làm giảm tỷ lệ ảnh hay nói cách khác độ phân giải mặt đất của ảnh thấp đi gây khó khăn việc phân biệt các đối tượng bề mặt hay chính là giảm độ chính xác của bản đồ. Máy ảnh hàng không kỹ thuật số dạng chụp khung hiện nay có giá thành rất đắt so với nền kinh tế của nước ta, mỗi máy chụp chỉ có một loại tiêu cự (máy thế hệ cũ như Ultracam XP W/A), và hai loại tiêu cự như Ultracam Eagle, nhưng giá thành cho mỗi loại tiêu cự cũng rất cao. Chính vì vậy, việc lựa chọn tiêu cự cho phù hợp địa hình cần thành lập bản đồ gặp phải những khó khăn và phải chấp nhận, thí dụ: khi chụp ảnh thành phố việc xác định tiêu cự dài (210mm chẳng hạn) nhằm giảm bớt sai số do các nhà cao tầng gây ra thì chúng ta vẫn phải chấp nhận sử dụng tiêu cự góc rộng $(70 \mathrm{~mm})$. Vì lẽ đó, việc xác định độ phân giải tương ứng với tỷ lệ bản đồ cần thành lập chỉ còn một yếu tố liên quan đó chính là yêu cầu độ chính xác độ cao (khoảng cao đều).

Xuất phát từ công thức kinh điển trong đo ảnh [1]: $\quad \mathrm{H}=\frac{\mathrm{b}}{m \Delta p} \mathrm{~m}_{\mathrm{h}}$

Trong đó: H: độ cao bay chụp $(m)$, b: đường đáy chụp ảnh $(\mathrm{mm}), \mathrm{m}_{\mathrm{h}}$ : sai số trung phương xác định độ cao cho phép $(\mathrm{m}), \mathrm{m}_{\Delta \mathrm{p}}$ : sai số trung phương xác định thị sai ngang (mm).

Trong đo vẽ ảnh số việc xác định thị sai ngang được chuyển sang tính theo kích thước Pixel (Px). Tùy theo chất lượng ảnh chụp giá trị này có thể khác nhau, với điều kiện khí tượng tốt, ảnh không bị nhiễu, sắc nét người ta có thể lấy giá trị này $1 / 3^{*} \mathrm{Px}$, trong tăng dày sử dụng phương pháp khớp ảnh tự động (MatchAT) cũng hay sử dụng giá trị 1/3* Px. Theo chúng tôi, ở Việt Nam 
với thời tiết nhiệt đới gió mùa, mây nhiều, độ ẩm cao ảnh chụp thường không có độ trong như ảnh chụp ở các nước châu Âu, Mỹ, Úc... và sử dụng để ước tính (có hệ số dự phòng) nên lấy bằng 1 pixel là hợp lý. Công thức trên có thể viết dưới dạng:

$$
\mathrm{H}=\frac{\mathrm{b}}{S_{p x}} \mathrm{~m}_{\mathrm{h}}
$$

Trong đó: H: độ cao bay chụp $(m), b$ : đường đáy chụp ảnh $(\mathrm{mm}), \mathrm{m}_{\mathrm{h}}$ : sai số trung phương xác định độ cao cho phép $(m), S_{p x}$ : sai số trung phương xác định thị sai ngang $(\mathrm{mm})$.

Như vậy, với máy ảnh hàng không kỹ thuật số dạng chụp khung cự thể, yêu cầu độ phủ của ảnh chụp... chúng ta có thể ước tính độ cao bay chụp, tỷ lệ ảnh, đường đáy chụp ảnh cũng như độ phân giải mặt đất của ảnh.

Sau đây là một số phương án tính toán xác định độ phân giải dựa vào yêu cầu độ chính xác xác định mặt phẳng và độ cao của tỷ lệ bản đồ với máy chụp ảnh số hàng không là loại máy Ultracam XP W/A có một số thông số kỹ thuật như sau: tiêu cự: 70.5 $\mathrm{mm}$, kích thước ảnh: $103.9 \times 67.8 \mathrm{~mm}$, kích thước Pixel trên CCD: $6 \mu \mathrm{m}$

2.2. Độ phân giải khi đo vẽ bản đồ địa hình tỷ lệ 1:2.000 khoảng cao đều $0.5 \mathrm{~m}$

Máy ảnh được thiết kế đồng bộ với GPS/INS và đặt trên máy bay với chiều dài của $C C D$ vuông góc với hướng bay, vì vậy khi tính toán độ phủ dọc, ngang tuyến bay chúng ta phải sử dụng kích thước máy ảnh ngược lại 67.8 x 103.9mm.

- Khi bay độ phủ dọc $60 \%$ :

$$
b_{60 \%}=67.8 \times 40 \%=27.1 \mathrm{~mm}
$$

- Sai số xác định độ cao $1 / 3$ khoảng cao đều: $m_{h}=1 / 3 * 0.5 m=0.17 m$

Thay vào (3) và lấy sai số trung phương đo thị sai ngang bằng $1 \mathrm{Px}(6 \mu \mathrm{m})$ tính được:
$\mathrm{H}_{\mathrm{bc} 60 \%}=754 \mathrm{~m}$, Tỷ lệ ảnh: 1:10.695

Độ phân giải mặt đất: $6 \mathrm{~cm}$ tương đương $0.03 \mathrm{~mm}$ ở tỷ lệ bản đồ 1:2.000

2.3. Độ phân giải khi đo vẽ bản đồ địa hình tỷ lệ 1:2.000 và 1:5.000 khoảng cao đều $1.0 \mathrm{~m}$

- Khi bay độ phủ dọc $60 \%$ :

$$
b_{60 \%}=67.8 \times 40 \%=27.1 \mathrm{~mm}
$$

- Sai số xác định độ cao 1/3 khoảng cao đều: $m_{h}=1 / 3$ * $1 m=0.33 m$

Thay vào (3) và lấy sai số trung phương đo thị sai ngang bằng $1 \mathrm{Px}(6 \mu \mathrm{m})$ tính được:

$H_{b c 60 \%}=1508 \mathrm{~m}$, Tỷ lệ ảnh: 1:21.390

Độ phân giải mặt đất: $13 \mathrm{~cm}$ tương đương $0.06 \mathrm{~mm}$ ở tỷ lệ bản đồ 1:2.000

\section{$0.03 \mathrm{~mm}$ ở tỷ lệ bản đồ 1:5.000}

2.4. Độ phân giải khi đo vẽ bản đồ địa hình tỷ lệ 1:5.000 với khoảng cao đểu $2.5 m$

- Khi bay độ phủ dọc $60 \%$ :

$$
b_{60 \%}=67.8 \times 40 \%=27.1 \mathrm{~mm}
$$

- Sai số xác định độ cao 1/3 khoảng cao đều: $\mathrm{m}_{\mathrm{h}}=1 / 3^{*} 2.5 \mathrm{~m}=0.83 \mathrm{~m}$

Thay vào (3) và lấy sai số trung phương đo thị sai ngang bằng $1 \mathrm{Px}(6 \mu \mathrm{m})$ tính được:

$\mathrm{H}_{\mathrm{bc} 60 \%}=3770 \mathrm{~m}$, Tỷ lệ ảnh: 1:53.475, Độ phân giải mặt đất: $32 \mathrm{~cm}$ tương đương $0.06 \mathrm{~mm}$ ở tỷ lệ bản đồ 1:5.000

3. Yêu cầu độ phân giải trong thành lập và hiện chỉnh bản đồ tỷ lệ 1:2.000 và 1:5.000

\subsection{Trong hiện chỉnh bản đồ địa hình tỷ lệ 1:2.000 và 1:5.000 \\ Trong hiện chỉnh bản đồ địa hình, thông thường chủ yếu chỉ đo vẽ các yếu tố địa vật mới xuất hiện độ cao ở đây chỉ làm nhiệm vụ cân bằng mô hình đảm bảo cho ảnh}


hưởng do chênh cao địa hình không ảnh hưởng đến độ chính xác đo vẽ địa vật. Vì vậy, khi bay chụp phục vụ cho công việc này chúng ta chỉ quan tâm đến độ chính xác xác định mặt phẳng có nghĩa là độ phân giải mặt đất được xác định sao cho có thể xác định rõ địa vật trên bản đồ. Với cách tiếp cận như vậy, con số đưa ra theo Jacobsen 0.05$0.1 \mathrm{~mm}$ ở tỷ lệ bản đồ có thể sử dụng giá trị lớn nhất $0.1 \mathrm{~mm}$ ở tỷ lệ bản đồ cho mục đích này.

Với phân tích như trên, chúng tôi đã lập ra bảng tính toán xác định độ phân giải cho công tác hiện chỉnh bản đồ hai loại tỷ lệ $1: 2.000$ và $1: 5.000$.

Công thức (1) là cơ sở để tính độ cao bay chụp cho hiện chỉnh bản đồ địa hình. Bảng 4 sau đây ước tính độ cao bay chụp trên các thông số kỹ thuật của máy Ultracam WP X/A với độ phân giải mặt đất (GSD) tính bằng $0.1 \mathrm{~mm}$ tỷ lệ bản đồ $1: 2.000$ và $1: 5.000$ là $20 \mathrm{~cm}$ và $50 \mathrm{~cm}$. (Xem bảng 4 )

Số liệu bảng 4 cho ta thấy nếu không quan tâm đến vấn đề xác định độ cao bằng công nghệ ảnh thì tỷ lệ ảnh giảm (độ cao bay chụp tăng hơn nhiều)

\subsection{Trong thành lập bản đồ địa hình tỷ lệ $1: 2.000$ và $1: 5.000$}

Qua phân tích ở các mục 2.2, 2.3, 2.4 ở trên sau khi tổng hợp các tính toán cho 3 loại khoảng đều $0.5,1,2.5 \mathrm{~m}$, tương ứng với 2 loại tỷ lệ bản đồ 1:2.000 và 1:5.000 ta

Bảng 4: Độ phân giải, độ cao bay chụp cho hiện chỉnh bản đồ

\begin{tabular}{|c|c|c|c|c|c|}
\hline $\begin{array}{c}\text { Độ phân giải } \\
(\mathrm{cm})\end{array}$ & Tỷ lệ bản đồ & Tiêu cự $(\mathrm{mm})$ & Pixel $(\mathrm{mm})$ & Tỷ lệ ảnh & Độ cao bay $(\mathrm{m})$ \\
\hline 20 & $1: 2.000$ & 70.5 & 0.006 & 33333 & 2350 \\
\hline 50 & $1: 5.000$ & 70.5 & 0.006 & 83333 & 5875 \\
\hline
\end{tabular}

Bảng 5: Mối quan hệ độ cao bay chụp, khoảng cao đều, độ phân giải hai loại tỷ lệ 1:2.000 và 1:5.000

\begin{tabular}{|c|c|c|c|c|c|c|c|c|}
\hline $\begin{array}{c}\text { Độ cao } \\
\text { bay }\end{array}$ & $\begin{array}{c}\text { Đường } \\
\text { đáy } \\
(60 \%)\end{array}$ & $\begin{array}{c}\text { Khoảng } \\
\text { cao đều }\end{array}$ & $\begin{array}{c}\text { Kích } \\
\text { thước } \\
\text { Pixel }\end{array}$ & Tiêu cự & Tỷ lệ ảnh & $\begin{array}{c}\text { GSD } \\
(60 \%)\end{array}$ & \multicolumn{2}{|c|}{$\begin{array}{c}\text { Tương đương }(\mathrm{mm}) \text { ỏ } \\
\text { tỷ lệ }\end{array}$} \\
\hline$(\mathrm{m})$ & $(\mathrm{mm})$ & $(\mathrm{m})$ & $(\mathrm{mm})$ & $(\mathrm{mm})$ & & $(\mathrm{cm})$ & $1: 2.000$ & $1: 5.000$ \\
\hline 754 & 27.144 & 0.5 & 0.006 & 70.5 & 10695 & 6 & 0.03 & 0.01 \\
\hline 1508 & 27.144 & 1 & 0.006 & 70.5 & 21390 & 13 & 0.06 & 0.03 \\
\hline 3770 & 27.144 & 2.5 & 0.006 & 70.5 & 53475 & 32 & 0.16 & 0.06 \\
\hline
\end{tabular}


có: (Xem bảng 5)

\section{Một số nhận xét}

Độ phân giải mặt đất của các loại tỷ lệ bản đồ phụ thuộc rất lớn vào độ chính xác xác định độ cao (khoảng cao đều)

Nếu bản đồ tỷ lệ 1:2.000 đo vẽ khoảng cao đều 1 mét, bản đồ tỷ lệ 1:5.000 đo vẽ khoảng cao đều 2.5 mét thì độ phân giải mặt đất tính theo tỷ lệ bản đồ $(0.06 \mathrm{~mm})$ đều nằm trong khoảng 0.05-0.1mm ở tỷ lệ bản đồ theo công bố của Jacobsen

Khi tính toán độ phân giải mặt đất cho hai loại tỷ lệ bản đồ có cùng khoảng cao đều, độ phân giải mặt đất của bản đồ tỷ lệ lớn hơn nằm trong khoảng $0.05-0.1 \mathrm{~mm}$ ở tỷ lệ bản đồ theo công bố của Jacobsen, bản đồ tỷ lệ nhỏ hơn nằm ngoài khoảng $(0.03 \mathrm{~mm})$.

Không có độ phân giải mang tính "trung gian" cho hai loại tỷ lệ bản đồ khi cùng đo vẽ 1 loại khoảng cao đều đường bình độ.

Ở Việt Nam, kể từ khi nhập thiết bị về qua thống kê các khu đo đã bay chụp, độ phân giải mặt đất khi bay chụp cho khoảng cao đều đường bình độ $1 \mathrm{~m}$, tỷ lệ bản đồ $1: 2.000$ khoảng 12 đến $13 \mathrm{~cm}$, khoảng cao đều $2.5 \mathrm{~m}$ tỷ lệ bản đồ 1:5.000 khoảng 25 đến $33 \mathrm{~cm}$. Các khu bay chụp trên đã được đưa vào sử dụng cho kết quả đảm bảo độ chính xác theo yêu cầu kỹ thuật chung về chất lượng sản phẩm đo đạc bản đồ.

Điều này cho thấy việc lấy giá trị sai số trung phương đo thị sai ngang là 1 pixel trong tính toán mối quan hệ độ cao bay, khoảng cao đều, độ phân giải hai loại tỷ lệ $1: 2.000$ và $1: 5.000$ trong nghiên cứu này là phù hợp với kết quả thu được từ thực tiễn. $\mathrm{O}$

\section{Tài liệu tham khảo}

[1]. Phạm Vọng Thành, 2000 Trắc địa ảnh (phần cơ sở chụp ảnh và chụp ảnh hàng không), Nhà Xuất bản Giao thông vận tải, Hà Nội

[2]. Derenyi, E. E. (1996) Photogrammetry: The Concept, Department of Geodesy and Geomatics Engineering, University of New Brunswick, Fredericton, N.B., Canada.

[3]. Jacobsen, K. (1998a) Image Scanner, Workshop on Mapping from Space, Ho Chi Minh City, October 26-30.

[4]. Jacobsen, K. (1998b) Requirements and Accuracy of Topographic Maps Produced from Space Imagery, Workshop on Mapping from Space, Ho Chi Minh City, October 26-30.

[5]. Light, D.L. (1996) Film Cameras or Digital Sensors? The Challenge Ahead of Aerial Imaging, Photogrammetric Engineering and Remote Sensing, Vol. 62, No. 3, pp. 285-291.

[6]. Produced by National space Development agency of Japan (NASDA)

[7]. Leica ADS80 Product Specifications từ WWW.leica-GeosystemsO 